\title{
Fatigue assessment of additively manufactured AlSi10Mg structures using effective stress concepts based on the critical distance approach
}

\author{
Kai Schnabel ${ }^{1}$ (D) Jörg Baumgartner ${ }^{1} \cdot$ Benjamin Möller $^{1} \cdot$ Matilde Scurria $^{1}$ \\ Received: 28 September 2020 / Accepted: 8 June 2021 / Published online: 2 August 2021 \\ (C) The Author(s) 2021
}

\begin{abstract}
In the last decade, Additive Manufacturing (AM) technologies have been considered by both the automotive and aerospace industries for the production of end-use metallic parts, with a main focus on Powder Bed Fusion - Laser Beam / metallic (PBF$\mathrm{LB} / \mathrm{M})$ technologies. However, AM parts present features that are deleterious to their cyclic properties. For a reliable design in terms of fatigue strength, existing influencing variables must be identified and transferred to a numerical model. In particular, different types of defects, as well as their distribution, should be taken into account. In addition to the identification of relevant parameters based on literature data, an AlSi10Mg component-like structure is assessed based on results from notched specimens and a linear-elastic assessment concept using effective stresses.
\end{abstract}

Keywords PBF-LB/M · Critical distance approach · Additive manufacturing $\cdot$ AlSi10Mg $\cdot$ Stress gradient

\section{Introduction}

Additive manufacturing (AM) technologies are still in a process of changing from rapid prototyping to a status of serial production of safety-relevant components. The usage of metallic materials, such as aluminum alloys, steels or titanium alloys, is especially relevant for lightweight-designed components with a high fatigue strength.

The main advantage of AM components is the design and manufacture of complex or branched structures with an ideal material utilization and optimized shape. Drawbacks, at present and in the near future, are the costs of additively manufactured components, especially for mass products. Small series with just a few parts per design are currently the focus of developments, because here the costs of tool production and changeover of the machines could be higher than the costs of the AM process.

Recommended for publication by Commission XIII - Fatigue of Welded Components and Structures

Kai Schnabel

Kai.Schnabel@lbf.fraunhofer.de

1 Fraunhofer Institute for Structural Durability and System Reliability LBF, Darmstadt, Germany
These considerations result, in most cases, in very specialized applications for AM parts. This often leads to small batches of parts. Cyclic testing is essential for quality control and characterization of the structure, but, in these cases, the costs related to long and expensive experimental campaigns may not be tolerable. Therefore, numerical-based concepts for the fatigue assessment of AM components are required.

Based on literature data, results of fatigue tests on AlSi10Mg specimens manufactured by Powder Bed Fusion - Laser Beam / metallic (PBF-LB/M) in different building directions show that pores and other defects in the subsurface area, as well as rough surfaces, are present in additively manufactured structures and lead to a reduction of the fatigue strength [1]. From a numerical point of view, it is hardly possible to reproduce all pores, defects and surface imperfections in a finite element model, since it requires an enormous number of elements to have a sufficient resolution of all pores. Furthermore, their presence and populations are not predictable. Also, on the one hand, it may not be possible to detect these defects appropriately by nondestructive testing in each AM-component and, on the other hand, it would not be costefficient.

Although the development of the production process is continuously improving, leading to a reduction of defects, these defects cannot yet be excluded, but vary in type and shape. 
Due to these typical existing defects in the structure or in the boundary of core and contour area, fracture mechanics approaches have been used for fatigue assessment [2-4]. However, it is difficult to determine the critical or so called "killer" defects [5]. In fact, it has been demonstrated that it is not always the "biggest" surface-defect in its dimensions that is also the critical one. Each defect would therefore have to be assessed individually.

Methods optimized for the fatigue assessment of additively manufactured components, which are based on stresses or strains and consider typical influencing factors such as stress gradients, have to be transferred to additively manufactured components.

Other methods that transfer the impact of defects on the local fatigue strength to an integral description without the explicit modeling of the defects are currently under development [6].

\section{Influencing factors on the fatigue strength}

The manufacturing process itself directly influences the type and amount of defects in additively manufactured structures, which are, in particular, decisive for their fatigue strength. Over 50 key process parameters in a PBF-LB/M-process can be identified $[7,8]$.

For the aim of this work, the important influencing parameters of applied energy per unit length, the distance between the welding beads and the contour runs are assumed. In fact, they play a major role in influencing the resulting microstructure and cooling rate, but also defect probability and distribution, as well as the overall building speed.

Other influencing parameters on the resulting microstructure and cooling rate, which can affect residual stresses, are the gas atmosphere used and the potential heating of the powder bed base by heating the building platform. Supporting structures have a strong influence on the topology of the surface, as well as the cooling rates.

The quality of the powder and its re-use level leads to different particle sizes and this can have an impact on the melting process within the welding beads and the morphology [9].

All parameters can directly depend on the orientation of the component in the manufacturing space.

As a result of the different process parameters, there are different structural properties, which lead to different fatigue strengths. Four groups of influencing factors on the fatigue strength can be defined:

Firstly, the surface quality is of particular relevance for the fatigue strength. In almost all fatigue tests on specimens with a nonmachined surface, the cracks start from the surface (Fig. 1,

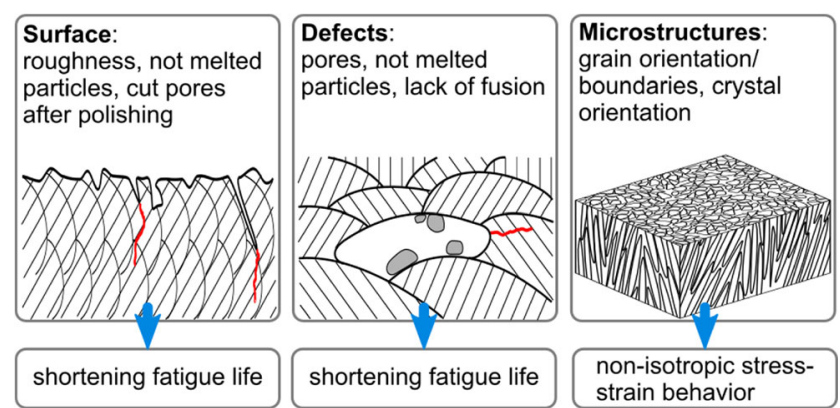

Fig. 1. Main influencing factors of fatigue life and structural behavior, which could be taking into account using finite-element models

left), which are introduced during the manufacturing process, $[1,10-13]$. The fatigue strength can depend on the size of a single layer [14], the building direction [11] and the exposure strategy or powder particles on the surface, which are not fully molten. This leads to a further increase in local stresses [15]. Polishing as-built structures carries the risk of cut subsurface pores, if the polishing is not sufficiently deep, [1]. In addition, special attention must be paid to surfaces with support structures.

A second influencing factor on fatigue strength, with the same importance as the surface quality, is the different kinds of internal defects, which may be responsible for crack initiation effects under cyclic loading. Especially in the case of a smooth and comparatively notch-free surface, failure originating from internal defects, e.g., pores, is typically observed, Fig. 1 (center). These occur depending on the particular production parameters. Both their size [16] and shape can vary greatly. In particular, large and sharp-edged defects, e.g., bonding defects or areas with powder particles that have not completely melted, lead to a strong increase in local stress and thus to a reduction in the fatigue strength. Some investigations show a more frequent occurrence of these defects in areas where two exposure regions meet, e.g., in the zone between the partially blurred border between contour and core material, $[3,17]$.

A third point, which is known from conventional materials, is the crucial influence of the microstructure on the stress- strain behavior and the fatigue strength. In particular, the size of the grains, the crystal orientation and segregations can lead to different structural properties. Due to the texture of the microstructure with a strongly directiondependent crystal formation, the material can behave nonisotropically. On the one hand, this can affect the mechanical properties, such as the tensor of elastic stiffness [2]. On the other hand, it can also affect the cyclic material behavior, e.g., hardening and softening $[18,19]$, and finally the fatigue strength.

A fourth, but difficult to handle, influencing factor is residual stresses [20], which are introduced during the manufacturing process, known from classical welding processes. In the 
case of tensile residual stresses, the fatigue strength can be significantly reduced [21]. For a reduction of residual stresses, heat treatments can be performed. For some materials, the heat treatment of stress relief annealing is a standard process, in order to reduce the residual stresses. Additionally, with the stress relief annealing, it is possible to alter the microstructure with the result of a better fatigue performance. Both effects are difficult to separate from each other. Attention must be paid to the fact that residual stresses may still be present despite a posttreatment.

Due to the layer-by-layer manufacturing of the components, the above-mentioned properties can be strongly non-isotropic. This depends on the base material used and the post-treatment. For example, non-isotropies evolve more strongly for Inconel® 718 compared to AlSi10Mg, [22-24].

AM production processes are being continuously optimized and developed, but, with present standard parameter sets, defects cannot be avoided. For this reason, additively manufactured components are frequently post-treated. Heat and surface treatments, as well as hot isostatic pressing, are typical post-treatment processes. All processes have an effect on some of the above-mentioned properties and, thus, on the fatigue strength. The challenge is to minimize the negative characteristics of the post-treatment processes, such as avoiding cut subsurface defects by polishing or flattening of pores to crack-like structures during hot isostatic pressing, if the oxide layer cannot be bonded in the pore, [25]. The question of a reasonable post-treatment for $\mathrm{AM}$ components requires the consideration of each individual component, in addition to (fatigue) strength aspects, also financial implications, because each post-treatment increases the financial expenditure.

\section{Special features in the design of additively manufactured metallic components}

Additively manufactured components have a special combination of properties and features, which have to be taken into account within a fatigue analysis. As mentioned above, these are, for example, the surface properties, the inherent defects, the microstructure and the residual stresses.

It is possible to evaluate the influence of the surface condition as well as the internal defects on the fatigue strength in a similar manner to that usually adopted with conventionally manufactured components. The decisive influencing factor in each case is the stress-raising effect of the macrogeometrical notches that are part of the design and the micro-geometrical notches, such as roughness and pores, which leads in combination to a reduction of the fatigue strength.
The first major challenge, however, is to obtain information on the irregularity distribution inside the part or the surface condition before its production. Correlations between process parameters and the irregularity distribution are basics for an efficient application.

The second major challenge is the microstructure. Firstly, similar to the irregularity distribution, information must be available on the microstructure that exists after production, depending on the process parameters and any subsequent heat treatment. The nonisotropic material and structural behavior are a major challenge here. Secondly, direction-dependent fatigue strength must also be available for certain materials.

The third major challenge is the mean stresses. Due to their potential impact on component durability, the intensity and location of residual stresses in the component should be known and they should possibly be attenuated. Although visible effects, in the form of component distortion, can be detected, local frozen, potentially harmful residual stresses can also remain hidden.

\section{Investigated specimens and component-like geometries}

For the fatigue assessment of AM components demonstrated for a component-like structure, fully reversed cyclic tests $(R=-1)$ were performed on un-notched and notched specimens. The component-like structures and the specimens were built under similar conditions from AlSi10Mg powder and with the standard process parameter set "AlSi10Mg performance" from 2016, including core and contour areas, Table 1. This should, in theory, result in comparable defect distributions and microstructures. Therefore, comparable characteristic parameters in the critical areas and similar characteristics are expected. In retrospect, however, the manufacturer cannot rule out the possibility that the gas flow was unsteady and, thus potentially, differences between different building jobs might be the outcome.

The flat specimens have a thickness of $t=2 \mathrm{~mm}$ and were built orthogonal to the building-platform (z-direction). No additional supporting structures are needed in this case. In total, three types of specimens with the nominal geometry shown in Fig. 2 are considered, which represent the different nominal fatigue notch factors of $K_{t}=1, K_{t}=1.7$, and $K_{t}=2.3$. Several specimens of all types, necessary for the fatigue investigation, were built in two batches (building jobs) called ALPHA and BRAVO, applying the same nominal process parameter set, Table 1 . The detailed geometries of the notches directly result from the melting of the base powder. No post-processing was performed, except for the removal of the specimens from the building platform. 
Table 1 Process parameters

\begin{tabular}{ll}
\hline Parameter & Value \\
\hline Machine & ConceptLaser M2 Single Laser \\
Parameter-set name & AlSi10Mg performance (2016) \\
Output & $370 \mathrm{~W}$ \\
Layer-thickness & $0.03 \mathrm{~mm}$ \\
Scanning speed & Core $=1500 \mathrm{~mm} / \mathrm{s}$, contour $=350 \mathrm{~mm} / \mathrm{s}$ \\
Hatch distance & $0.105 \mathrm{~mm}$ \\
Order & First contour, second core \\
Building-platform heating & Without \\
Direction of jetstream & Linear, powder-chamber to overflow-chamber \\
Residual oxygen level & Max. $0.5 \%$ (nitrogen atmosphere) \\
Heat-treatment & none \\
\hline
\end{tabular}

The component-like structure is designed to represent a more complex geometry than geometries at specimen level, but it is still a simplified design compared with a completely topology-optimized real part for application in the automotive industry, for example. It is built out of a base plate so that it can be easily clamped in a test setup. The base has dimensions of $120 \mathrm{~mm} \times 120 \mathrm{~mm}$ and its overall height is $165 \mathrm{~mm}$, Fig. 3 . Regarding its fatigue behavior, it is designed to have the failure inside the "legs" under bending loading. Four "legs" merge together to one "head", where the fully reversed cyclic loading $(R=-1)$ has been applied in the y-direction. The necessary support structures were placed in non-critical areas below the "head". As a standard post process for cleaning the part, the surface was blasted with glass beads with a size of $200-300 \mu \mathrm{m}$ at a pressure of $500 \mathrm{kPa}$, which is intended to clean the surface from adhering powder particles without inducing crucial compressive residual stresses to the component.

The transition area of the first layer, which is denoted as "shrink line", where the four legs unite, is visible to the naked eye, but not critical under the fatigue load, Fig. 3. The component-like structures were built in groups of four by

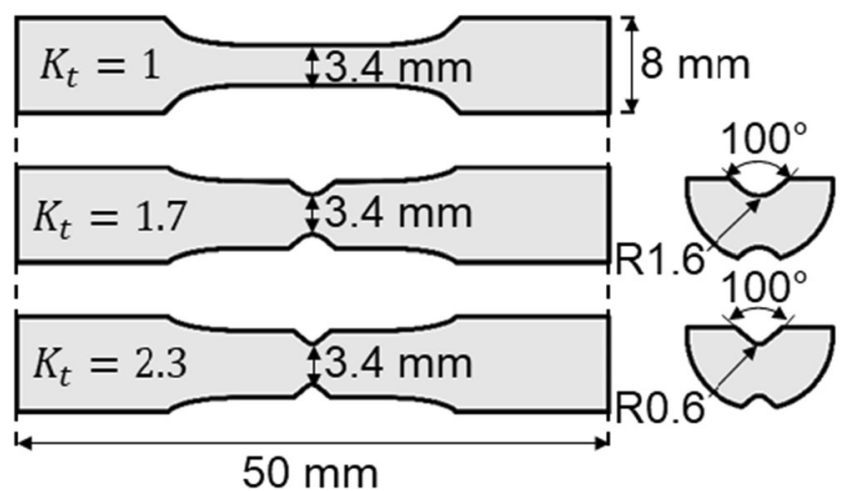

Fig. 2. Small scale flat specimen geometries different building jobs denoted as batch CHARLIE with the same nominal parameter set, which was used for the batches ALPHA and BRAVO.

In order to save production time and costs with respect to a post treatment of components, e.g., by grinding or milling, the fatigue assessment should be performed for net-shaped components based on net-shaped specimens in order to demonstrate the assessment for the net-shape component-like structures. Therefore, dimensions can differ from the nominal dimensions, which are referred to in this paper. Additive manufacturing of the net-shaped un-notched and notched specimens using the process described earlier merely results

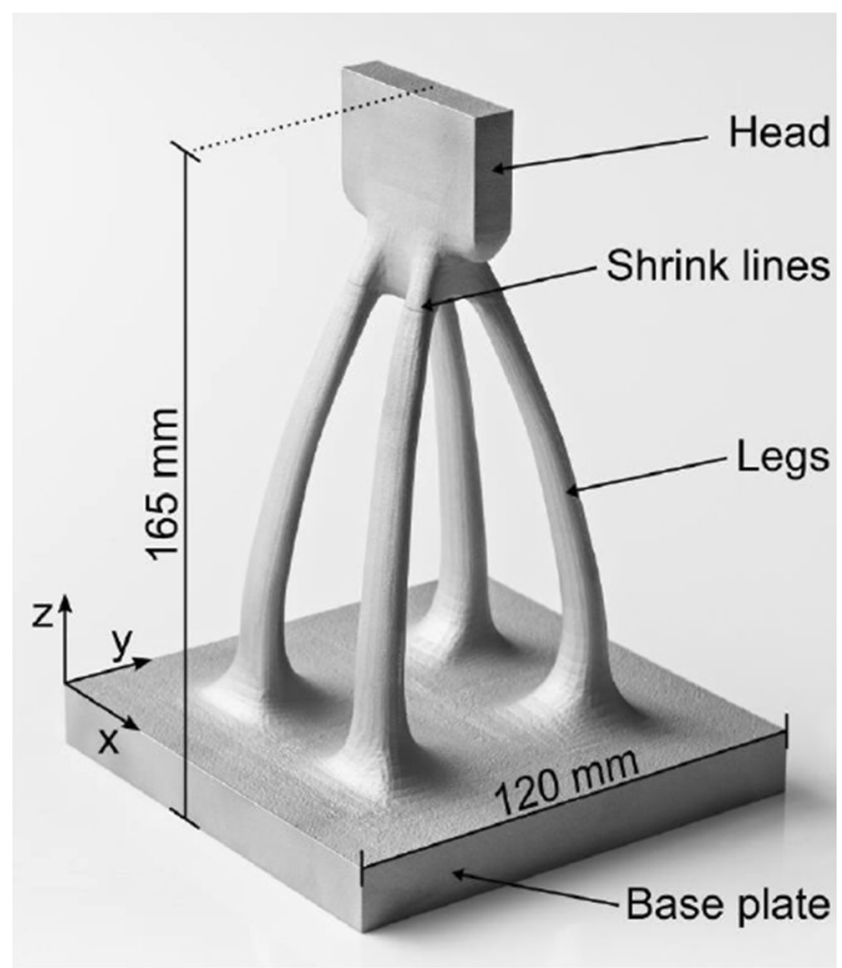

Fig. 3 Component-like structure for the fatigue assessment 
in real geometries differing from the nominal dimensions referred to in Fig. 2. The differences are negligible for flat surfaces in relation to larger dimensions, but increase at the notch roots, where the real notch radius decreases, for example, as described in $[1,26]$. In these investigations, the same types of specimens and nominal geometries were used and local geometries of the notches resulting from AM were investigated in detail. However, the effective stress concept used here employs nominal geometries as a basis for the fatigue assessment, which are the outcome of a component's design phase. Deviations of net-shaped components from the nominal geometry should be part of future analyzes, on the one hand, and their reduction the object of systematic process optimizations, on the other hand.

\section{Metallographic analyzes}

In order to analyze and compare the microstructures and defect distributions of specimens and components, section cuts have been prepared and etched with phosphoric acid (H3PO4) at $40^{\circ} \mathrm{C}$.

In the case of the specimens, the core area is mostly free from pores and shows relatively regular melting pools, Figs. 4 and 5. However, inside the contour area, pores of different size are present. The contour area itself has a thickness of $t_{\text {contour }} \approx$ $0.4 \mathrm{~mm}$ and has a different microstructure compared with the core.

These differences are due to the use of different scan strategies and process parameters when scanning these two areas of a specimen or part. For each layer, in fact, the contour is manufactured first using a lower scan speed of $350 \mathrm{~mm} / \mathrm{s}$, instead of the $1500 \mathrm{~mm} / \mathrm{s}$ used for the core, which is applied in order to improve the resulting surface roughness. A scan without a contour would result in higher surface roughness. Moreover, while the core pattern is shifted after each layer in order to avoid overlapping of the laser vectors, the contour is scanned following the same path layer after layer. The inner areas of the melt pools, visible in the core zone and represented in Fig. 4 (location I), indicate a fine equiaxed microstructure resulting from the high cooling rates typical for PBF-LB/M. However, along the melt pool boundaries, the microstructure is coarser, as denoted by lighter border lines. This effect is attributed to the lower cooling rates resulting in the overlapping region of two adjacent melt pools, where the temperatures remain higher for a longer time [27]. The contour area, on the other hand, is characterized by a dendritic microstructure. In the contour area (Location II) of Fig. 4, it is easy to distinguish between the silicon ( $\mathrm{Si})$ dendrites (white) and the $\alpha$-aluminum (Al) matrix (dark gray). However, the reason for the formation of a dendritic structure rather than a cellular one in PBF-LB/M AlSi10Mg is still unclear [28]. In general, the solidification process can be divided into a first stage, corresponding to the solidification of the $\alpha$-Al matrix, and a second one, in which the $\mathrm{Si}$ is driven out from Al. During this second phase, the Si accumulates along the boundaries and solidifies [28].

For the "legs" of the components, which are expected to fail in the cyclic fatigue tests, two micro-sections have been prepared. The first section cut is orthogonal to the building direction. It shows an approximately constant thickness of the contour area along the circumference and pores inside the contour area and in the transition between the contour and the core (Fig. 6). Especially under cyclic bending loading, these pores could become critical. Because of the fact that the section cut is not exactly positioned within one building layer, the rotation of the melting direction layer-by-layer which should reduce anisotropic mechanical behavior - is only partly visible in the checkerboard pattern.

The second section cut has been made along the "leg", parallel to the build direction. Basically, the results found from the first cut can be transferred to this micro-section and the entire leg in the longitudinal direction (Fig. 7). Some pores are also visible in the core area, which are probably due to the checkerboard pattern used, since this building strategy may increase the probability that pores are created at the connection lines of the individual fields.

From the point of view of these investigations, the properties of the specimens and components appear to be very similar.

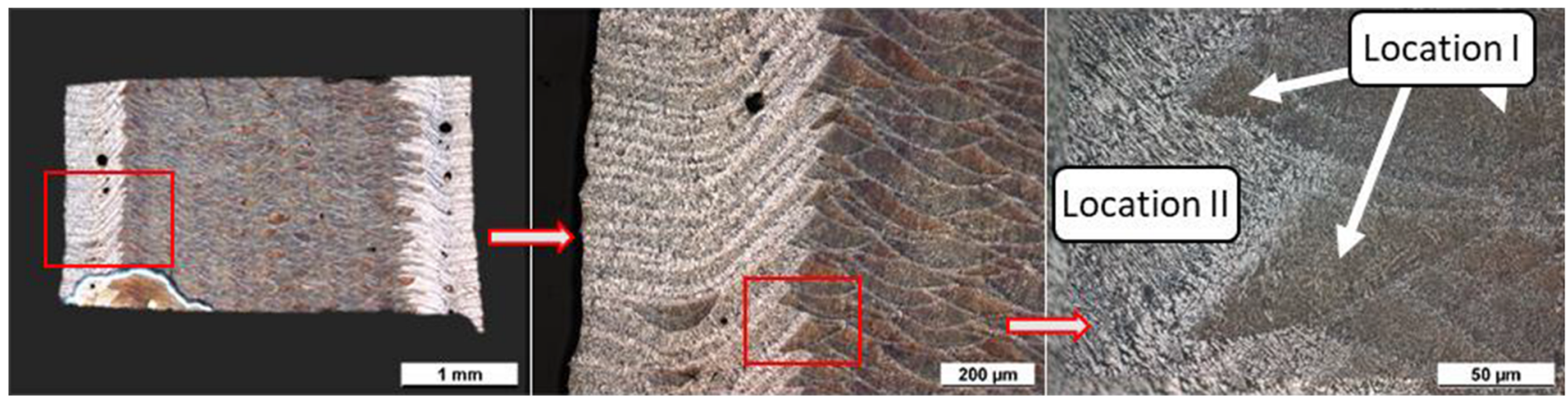

Fig. 4. Etched section cut orthogonal to the build direction showing the microstructure in the area of the contour and core; Location I: fine equiaxed microstructure, Location II: coarse dendritic microstructure 


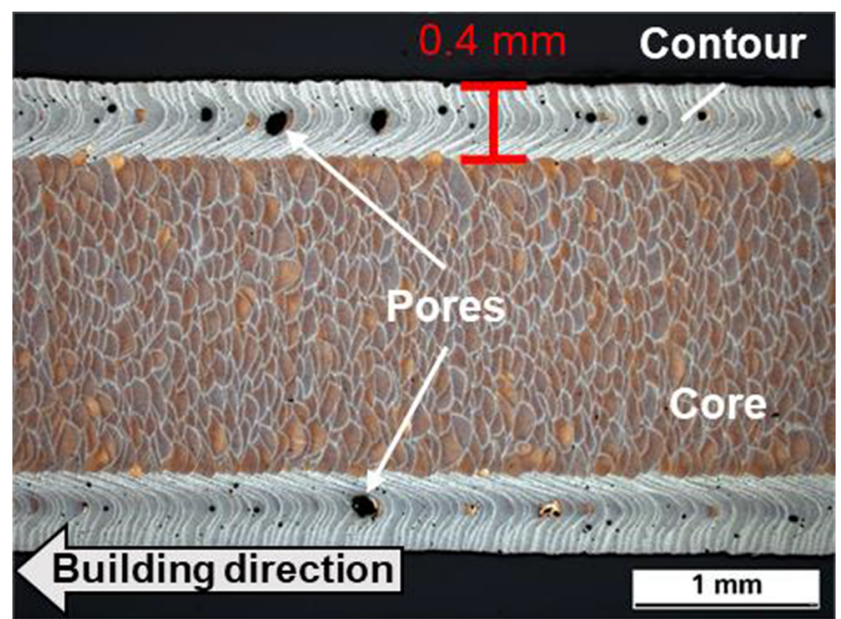

Fig. 5 Etched microsection of an AlSi10Mg specimen without support structures showing pores inside the contour area

However, a difference between the individual building jobs can be seen in hardness measurements, Fig. 8. Independent of the building job, the contour area has a lower hardness than the core area, due to the different microstructure (see Fig. 4). The lowest hardness overall (contour and core) is found in the specimen of building job ALPHA. The specimen of building job BRAVO has a similar to slightly higher hardness in the contour area compared with the component of building job CHARLIE, but shows the highest hardness of approx. 160 HV0.1 in the core area, where the component (CHARLIE) has a lower hardness and is intermediate between the two specimens. This indicates that the structures from the different building jobs differ from each other.

\section{Roughness measurements}

For each specimen type and building job, typical specimens were examined with regard to their surface roughness. The measurements were made in the area of the test cross section, which corresponds to the global roughness of the specimen, and additionally in the notch root for notched specimens, where the failure occurs. In addition to roughness measurements of un-notched and notched specimens, the surface roughness of both failure regions of the component-like structure was determined by measurement of the surface profile using a stationary high precision measuring roughness and contour instrument and evaluation of the arithmetical mean roughness index $R_{a}$ and the maximum peak-to-valley height roughness index $\mathrm{R}_{\mathrm{z}}$. For two of the investigated components, V03 and V05, roughness measurements were performed on the surfaces of the legs facing away from each other ("outside" and "side" faces) and directed to each other ("inside"). Roughness measuring tracks on the "outside" of components V03 and V05 are sketched as black lines in Fig. 9.

All measured tracks are oriented along the longitudinal axis of the leg, if possible. The results of the roughness measurements are summarized in Table 2 . The roughness is documented by the mean value of various measuring tracks and the corresponding standard deviation. In the test section of unnotched specimens and the root of notched specimens relevant for fatigue failure, measured mean values of both the averaged arithmetical mean index and maximum peak-to-valley height roughness index of batch ALPHA show a lower roughness than batch BRAVO. Surprisingly, it becomes obvious that the roughness in the notch base of the notched specimens is strikingly lower than the global roughness outside the notch and of un-notched specimens. The low roughness has the positive effect that the additively manufactured geometry approximates the nominal one quite well, while it is still the prior location for the fatigue failure.

In the section "Experimental fatigue investigation of components" different so-called failure regions for the components are introduced. On the one hand, the measurement results show that the averaged arithmetical mean roughness of failure region " $\mathrm{A}$ " $\left(\mathrm{R}_{\mathrm{a}}=3.1\right)$ is almost equal than failure region " $\mathrm{B}$ " $\left(R_{a}=3.3\right)$, while $R_{z}$ shows the opposite. On the other hand, it
Fig. 6 Etched microsection of a section cut orthogonal to the longitudinal axis of one component "leg"

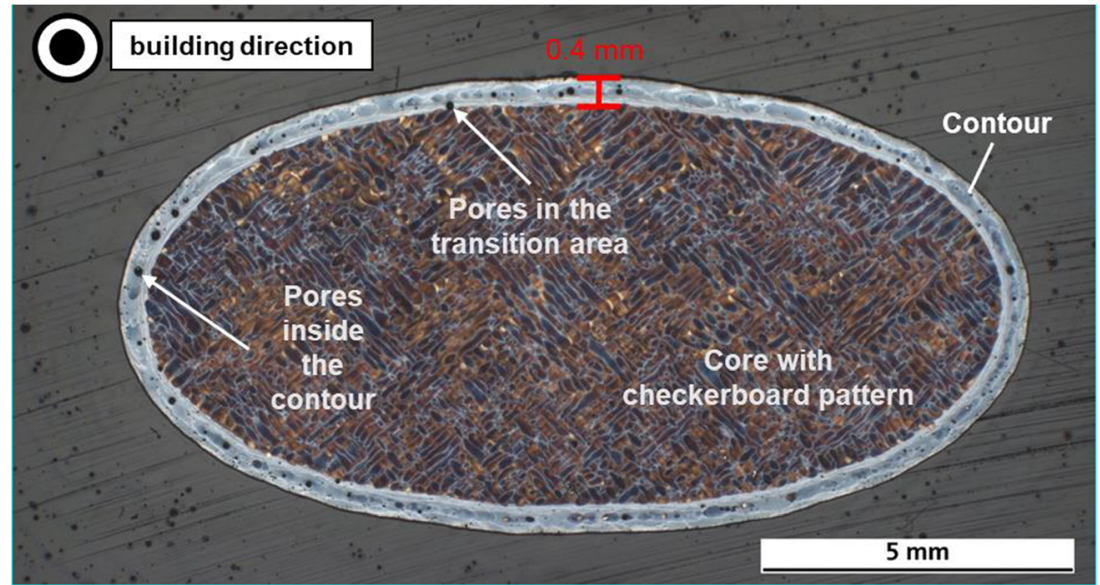


Fig. 7 Etched microsection of a section cut along the longitudinal axis of the component "leg"

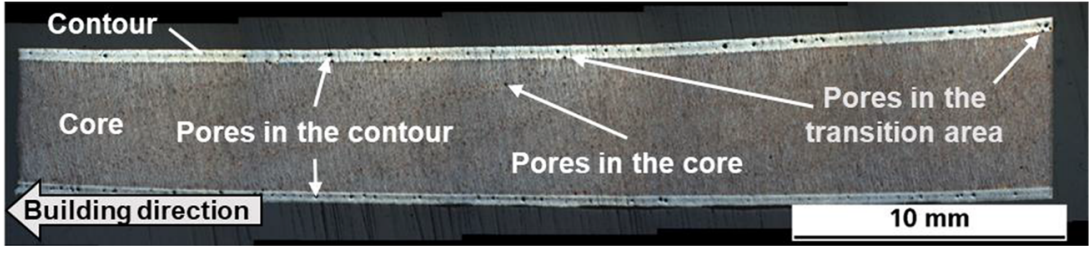

has been found that component V03 shows a slightly higher roughness of $\mathrm{R}_{\mathrm{a}}=3.3$ on average compared with $\mathrm{V} 05\left(\mathrm{R}_{\mathrm{a}}=\right.$ 3.1).

As a good basis for the transferability of the fatigue approach from specimens to components, all measurement results show that there is very little difference between the global roughness of specimens and components. However, it should be noted that roughness indices as a result of measurements comprise limited information on the surface profile and might disregard critical sharp surface notches, e.g., described in more detail by Persenot et al. [5].

\section{Experimental fatigue investigation of specimens}

The specimens for the cyclic tests were built in two different batches with the same process parameter set 'AlSi10Mg performance 2016'. Both batches were tested under force control on a piezo-electric test-rig in fully reversed tensile loading conditions $R_{\mathrm{F}}=-1$ using test frequencies of $f=100 \mathrm{~Hz}$ until rupture of the specimens. Nevertheless, the test results and evaluated S-N curves show that the fatigue strength of the

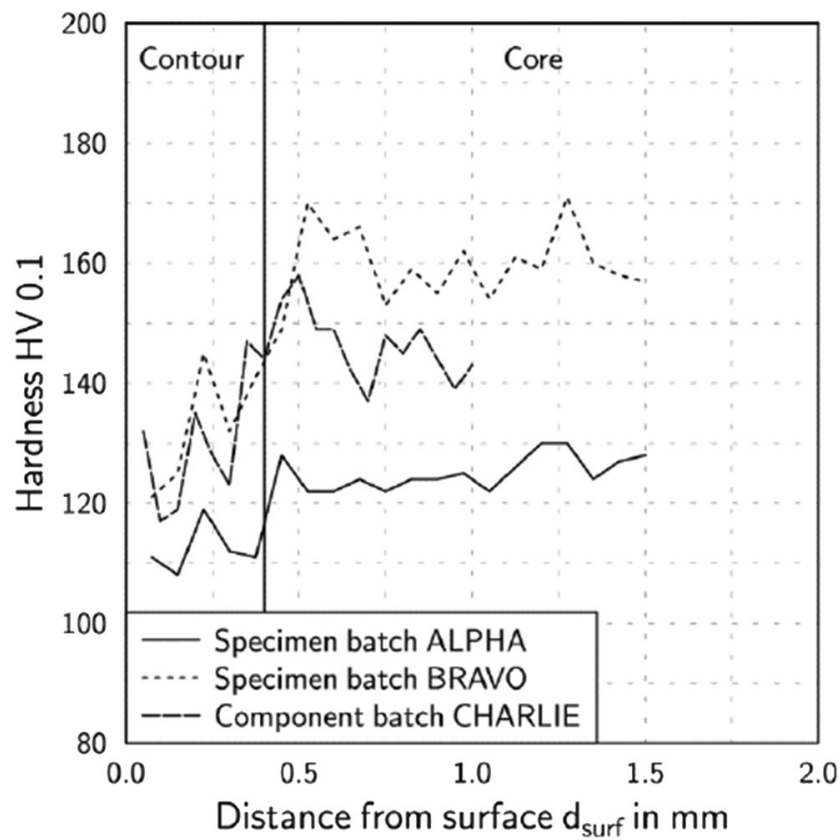

Fig. 8 Characteristic curves of micro hardness from the surface (contour) normal into the specimen or component (core) specimens from batch ALPHA is approximately three times higher than that of batch BRAVO.

In order to be able to find a reference $\mathrm{S}-\mathrm{N}$ curve by means of effective stresses, the tests are evaluated using the maximum likelihood estimation [29]. S-N curves, with a defined knee point at $N_{\mathrm{k}}=3 \cdot 10^{5}$ cycles and slopes of $k=7$ before the knee point and, according to [30], a slope $k^{*}=22$ for aluminum alloys after the knee point, have been evaluated from the fatigue test results of each specimen type (un-notched and notched) for batch ALPHA, Fig. 10.

In the nominal stress system and in the case of the S-N curves of batch ALPHA, the expected order for the different sharp notches is present: starting with the highest fatigue strength of $S_{\mathrm{k}}=120 \mathrm{MPa}$ for the un-notched specimens $\left(K_{\mathrm{t}}=1.0\right)$ and going down to lower fatigue strengths of $S_{\mathrm{k}}=$ $99 \mathrm{MPa}\left(K_{\mathrm{t}}=1.7\right)$ and $S_{\mathrm{k}}=70 \mathrm{MPa}\left(K_{\mathrm{t}}=2.3\right)$ with increasing stress concentration, Fig. 10 (left). However, the scatter of test results is between $T_{\sigma}=1: 1.27$ and $T_{\sigma}=1: 1.37$.

S-N curves, with a defined knee point at $N_{\mathrm{f}}=1 \cdot 10^{6}$ cycles and slopes of $k=6$ before the knee point and $k^{*}=22$ after the knee point, have been evaluated from the fatigue test results of each specimen type (un-notched and notched) of batch BRAVO, Fig. 10 (right). The resulting S-N curve is, as before, evaluated using the maximum likelihood estimation. On the one hand, the results from batch BRAVO overall show a lower fatigue strength than those from batch ALPHA. On the other hand, an unusual behavior regarding the notch effect can be identified. The un-notched specimens with $K_{\mathrm{t}}=1$ show a slightly lower fatigue strength of $S_{\mathrm{k}}=41 \mathrm{MPa}$ compared

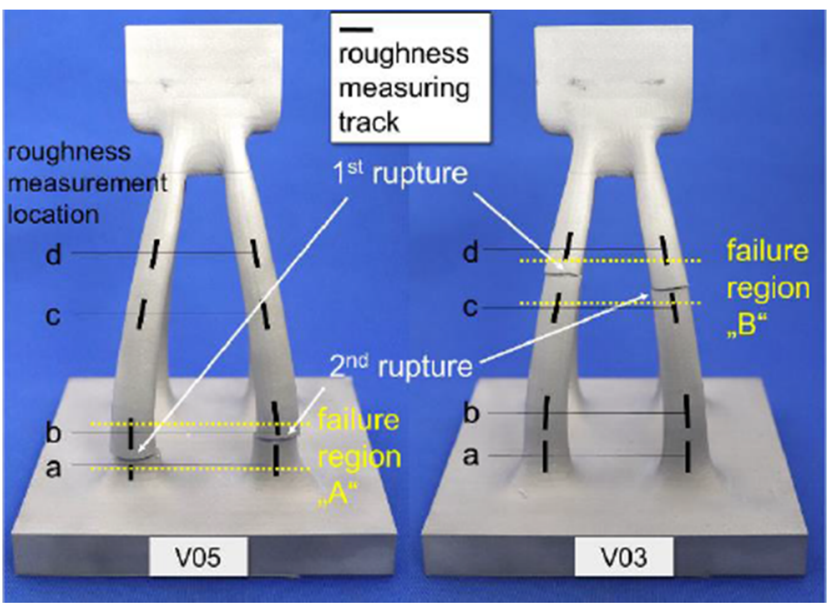

Fig. 9 Typical failure regions and roughness measuring tracks of the investigated components 
with $S_{\mathrm{k}}=45 \mathrm{MPa}$ for the mild-notched specimen with $K_{\mathrm{t}}=$ 1.7. This indicates that the micro-geometrical notches, i.e., the defects such as pores, in case of the $K_{\mathrm{t}}=1$ specimen have a similar notch effect to the macro-geometrical notches including the micro-geometrical notches of the specimens with $K_{t}=$ 1.7. The surface roughness shows no abnormalities, Table 2 . However, the $K_{\mathrm{t}}=2.3$ specimens show the lowest fatigue strengths of $S_{\mathrm{k}}=30 \mathrm{MPa}$, where the macro-geometrical notches seem to be the dominating effect on fatigue performance. The scatter of these test results is similar to that of batch ALPHA with a maximum of $T_{\sigma}=1: 1.38$. It should be noted that the calculated scatter may vary, if each S-N curve is calculated separately with free variation of slopes and knee point positions.

A difference in the fatigue strength between batch ALPHA and batch BRAVO has been found, which cannot be explained by the use of different nominal process parameters. A difference in the micro hardness $H V 0.1$ was shown in the previous section "Metallographic analyzes". While the hardnesses of batch BRAVO and CHARLIE are close to each other, especially in the critical area of the contour, it is obvious that the hardness of batch ALPHA, which shows a higher fatigue strength than batch BRAVO, is significantly lower (core and contour area). Furthermore, it was found that the surface roughness of batch ALPHA is slightly lower in fatigue-relevant cross sections and notch roots that the roughness of batch BRAVO.

\section{Experimental fatigue investigation of components}

Seven component-like structures have been tested under fully reversed $\left(R_{\mathrm{F}}=-1\right)$ bending load on a servo-hydraulic test rig (Fig. 11) using frequencies of $f=20 \mathrm{~Hz}$ up to a displacement $>$ $2 \mathrm{~mm}$, where at least a rupture of one leg has been found due to the bending stiffness reduction of the component - in some cases corresponding to the rupture of two legs. One component was tested for more than $N_{\mathrm{f}}=1 \cdot 10^{7}$ cycles without any visible failure and is therefore marked as a run out (cf. horizontal arrow in Fig. 12).

During fatigue testing, the "legs" of the structures were continuously observed by a camera monitoring system. By evaluation of images taken equidistant in time, the numbers of cycles corresponding to crack initiation and rupture of the first "leg" were tracked. Secondary "leg" failure, as also shown by the typical bending fatigue failures in Fig. 9 was disregarded as a failure criterion. The location of the failures was observed in two regions (Fig. 9): the first one close to the base plate and a second one closer to the head of the component. Measured from the top of the baseplate in z-direction, the region between $z=12.5 \mathrm{~mm}$ and $z=22.5 \mathrm{~mm}$ is referred to as 

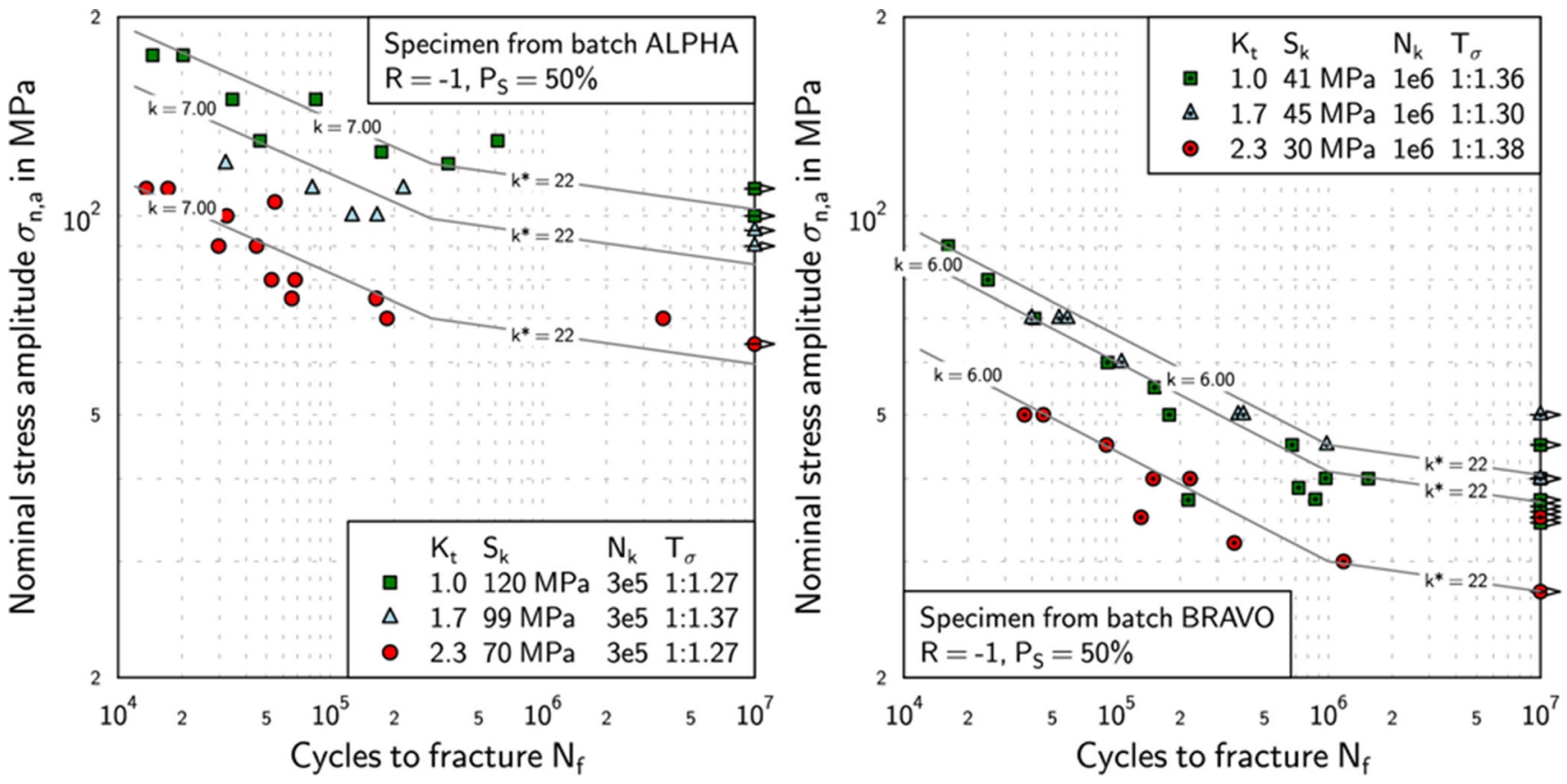

Fig. 10 Evaluated test results of the un-notched and notched specimens of batch ALPHA (left) and batch BRAVO (right)

failure region " $\mathrm{A}$ " and the region between $z=67.2 \mathrm{~mm}$ and $z=77.5 \mathrm{~mm}$ is referred to as failure region "B", Table 3 .

The results of the component-like structures in both failure regions neither show remarkable differences in fatigue strength nor in the cycles to failure. Therefore - and because of the few results - both failure regions are evaluated by a single S-N curve using the maximum likelihood estimation. The resulting estimation of the S-N curve $\left(F_{\mathrm{k}}=1.4 \mathrm{kN}\right.$ at $N_{k}=$ $5 \cdot 10^{5}$ ) for this limited number of test results is shown in Fig. 12 and has a scatter of $T_{\sigma}=1: 1.26$, which is in the range of the lowest scatter of batch ALPHA. A second result related to

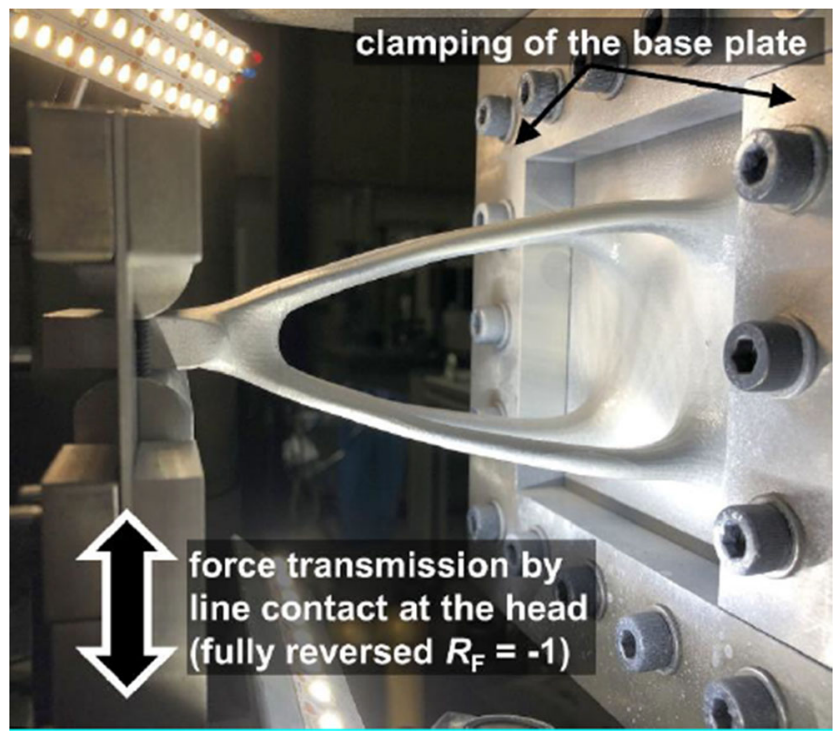

Fig. 11 Fatigue test setup for AM component testing the components becomes visible by analysis of the failure: All failed legs show some misalignment of the crack surfaces, Fig. 9. This indicates that there must have been residual stresses in the component, which were most likely introduced during the additive manufacturing process and which have been released after full fracture of the legs in terms of deformation of the legs.

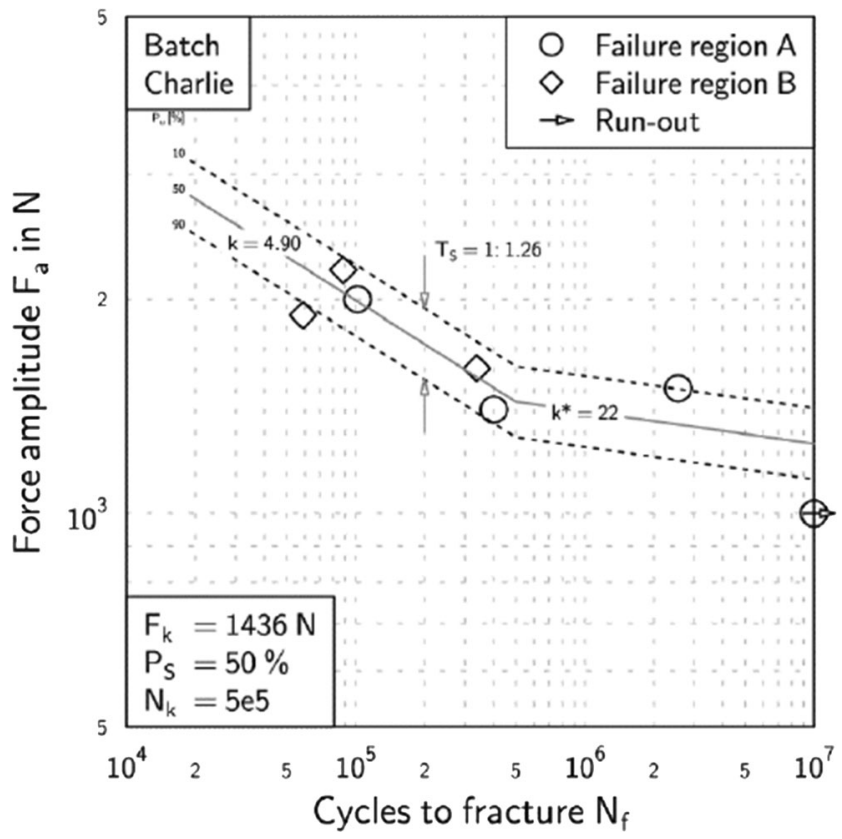

Fig. 12 Evaluated S-N curve from fatigue test results of the componentlike structure of batch CHARLIE 


\section{Numerical investigation}

For the two notched specimens, three-dimensional finite-element models are set up taking advantage of two symmetry planes. The boundary conditions are modeled as they are in the experiment, Fig. 13. The material model is linear elastic with a Young's modulus of $E=70 \mathrm{GPa}$ and a Poisson's ratio of $\nu=0.33$. The mesh is based on 20-node brick elements with quadratic shape function.

The normalized stress gradients $\eta(1)$, which depend on the distance from the surface $d_{\text {surf }}$, that are needed for further calculations are evaluated for both notched specimens, Fig. 14. The related stress gradient $G(2)$ is given by [31] .

$\eta=\frac{\sigma\left(d_{\text {surf }}\right)}{\sigma\left(d_{\text {surf }}=0\right)}$

$G=\frac{1}{d_{\text {surf }}} \cdot(1-\eta)$

The full model of the component is set up using 10-node tetrahedral elements with quadratic shape function. The clamping system is modeled by locking the translatory degrees of freedom in the area of the baseplate. The force transmission is effected by a clamping system with very thin steel sheets to achieve a bending moment reduced load introduction, Fig. 16. This system is also modeled to reproduce the correct stiffness. The material model is linear elastic with a modulus of elasticity of $E=70 \mathrm{GPa}$ and a Poisson's ratio of $\nu=0.33$, as well.

A submodel of one leg is set up by extruding its surface to the inner area by $1 \mathrm{~mm}$, Fig. 15. By this approach, reliable maximum stresses and stress gradients can be achieved. The submodel does not take into account any differences between contour and core structure. It consists of 20-node brick elements with quadratic shape function. The element size has a bias starting from $0.05 \mathrm{~mm}$ to $0.13 \mathrm{~mm}$ in the gradient direction, using 12 elements. A comparison of the strain on the submodel and measured strain on the real component using strain gages shows very good agreement, so it can be assumed that the finite-element model can represent reality, Fig. 16.

Within the finite-element model, the competing character in terms of stresses of failure region $\mathrm{A}$ and failure region $\mathrm{B}$ can be shown. The difference in the maximum stress is approximately $8 \%$ between the two regions. This difference in the

Table 3 Failure locations from the baseplate of the components

\begin{tabular}{llllllll}
\hline & V01 & V02 & V03 & V04 & V05 & V06 & V07 \\
\hline z-position in mm & 22.5 & 12.5 & 67.2 & 77.5 & 13 & - & 75 \\
Failure region & A & A & B & B & A & run-out & B \\
\hline
\end{tabular}

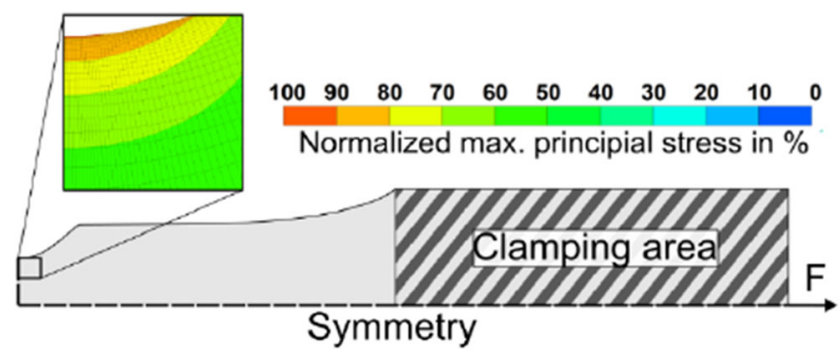

Fig. 13 FE-Modell of the $K_{t}=1.7$ specimen with normalized stress gradient

stress appears in both the failure region $\mathrm{A}$ and the failure region $\mathrm{B}$. This indicates that not the maximum stresses alone are governing the endurable stresses. Besides the maximum stress, the local gradients are considered. At the measured spots where the components have failed (Table 3), the stress gradients are evaluated and normalized, Fig. 17. As further influencing factors, the stress gradients and, subsequently, the microstructural support are considered. However, the gradients are very similar at both failure regions A and B. By looking at the dimensions of the highly stressed surface, also statistical influences need to be addressed. Nearly all the different failure spots are located inside the highest stressed volume of $\mathrm{V}=90 \%$ [32], which is often used to describe statistical size effects. Due to the quite heterogeneous distribution of pores, a volume of $80 \%$ [33], might also be better applicable to describing the statistical influence. Due to the lack of experimental data, further investigations on the statistical size effect were not performed.

It can be assumed that different critical subsurface defects in each component, which are distributed over the complete legs of the component as seen in the "Metallographic

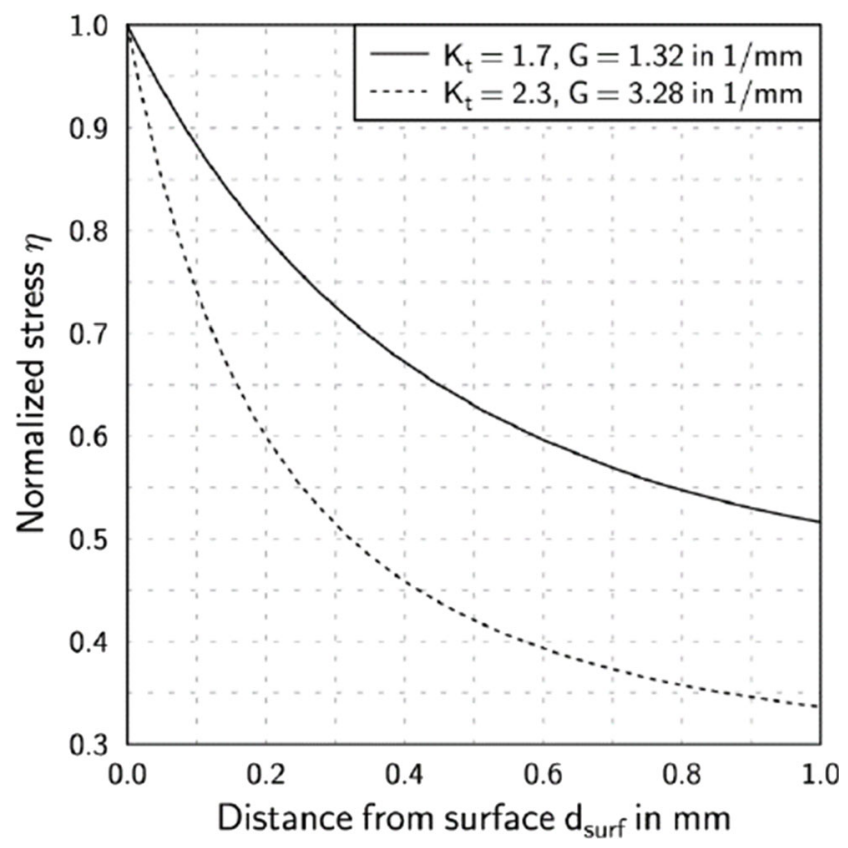

Fig. 14 Stress gradients of the notched specimen 


\section{Full-model}

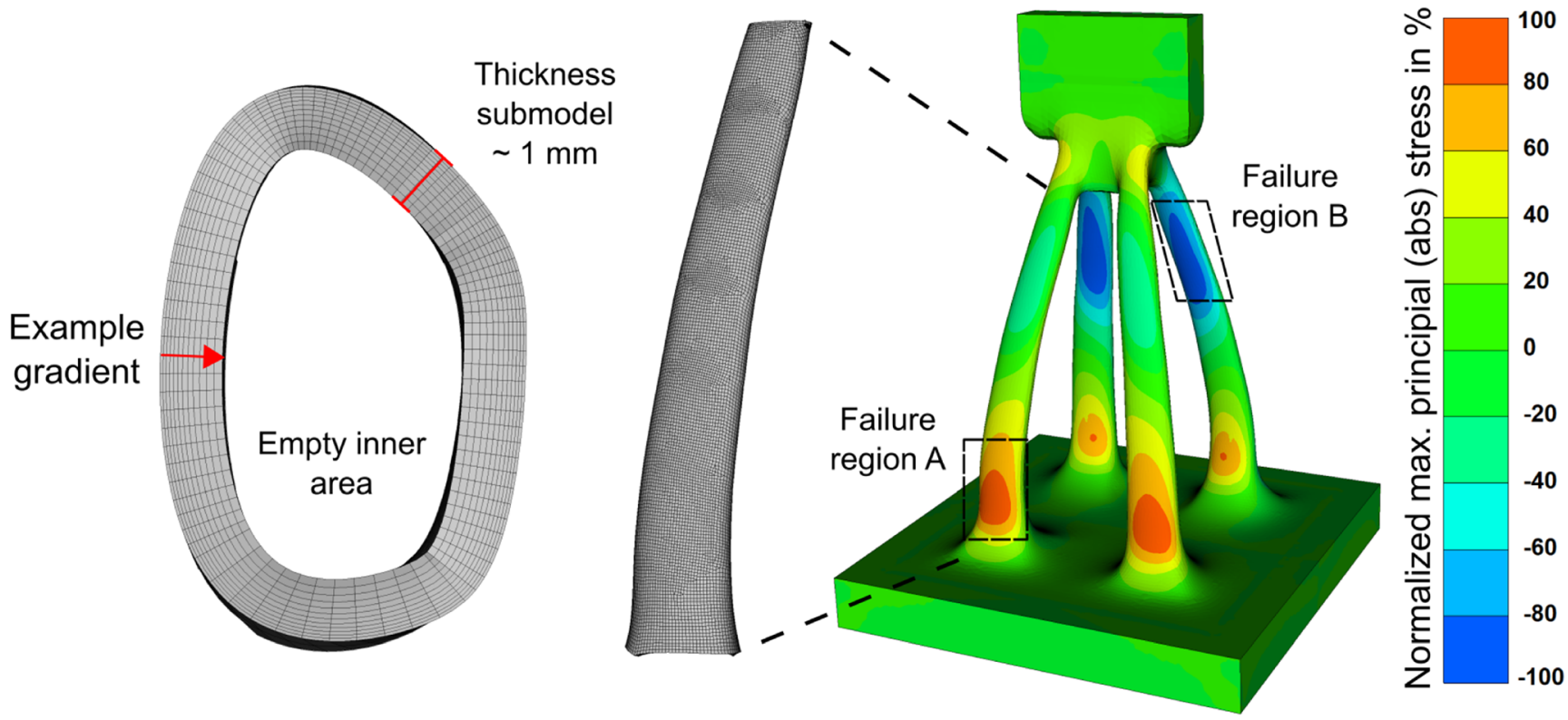

Fig. 15 Full-model and sub-model of the component and stress distribution

analyzes" section, are responsible for the respective failures and therefore lead to the different failure spots and regions.

\section{Assessment approach based on effective stresses}

The fatigue assessment is based on the critical distance approach using effective stresses in a critical distance, which has to be determined for each material and can consider notches of any different geometries, including stress concentrations on components [34]. This approach will be tested to see if it can be used to estimate the real fatigue strength of the components based on notched samples.

Using the experimental specimen results and the calculated stress gradients, the assessment S-N curve for the effective stress amplitudes $\sigma_{a \text {, eff }}$ is calculated. Firstly, the nominal local stresses in the notches of the specimen at the different load

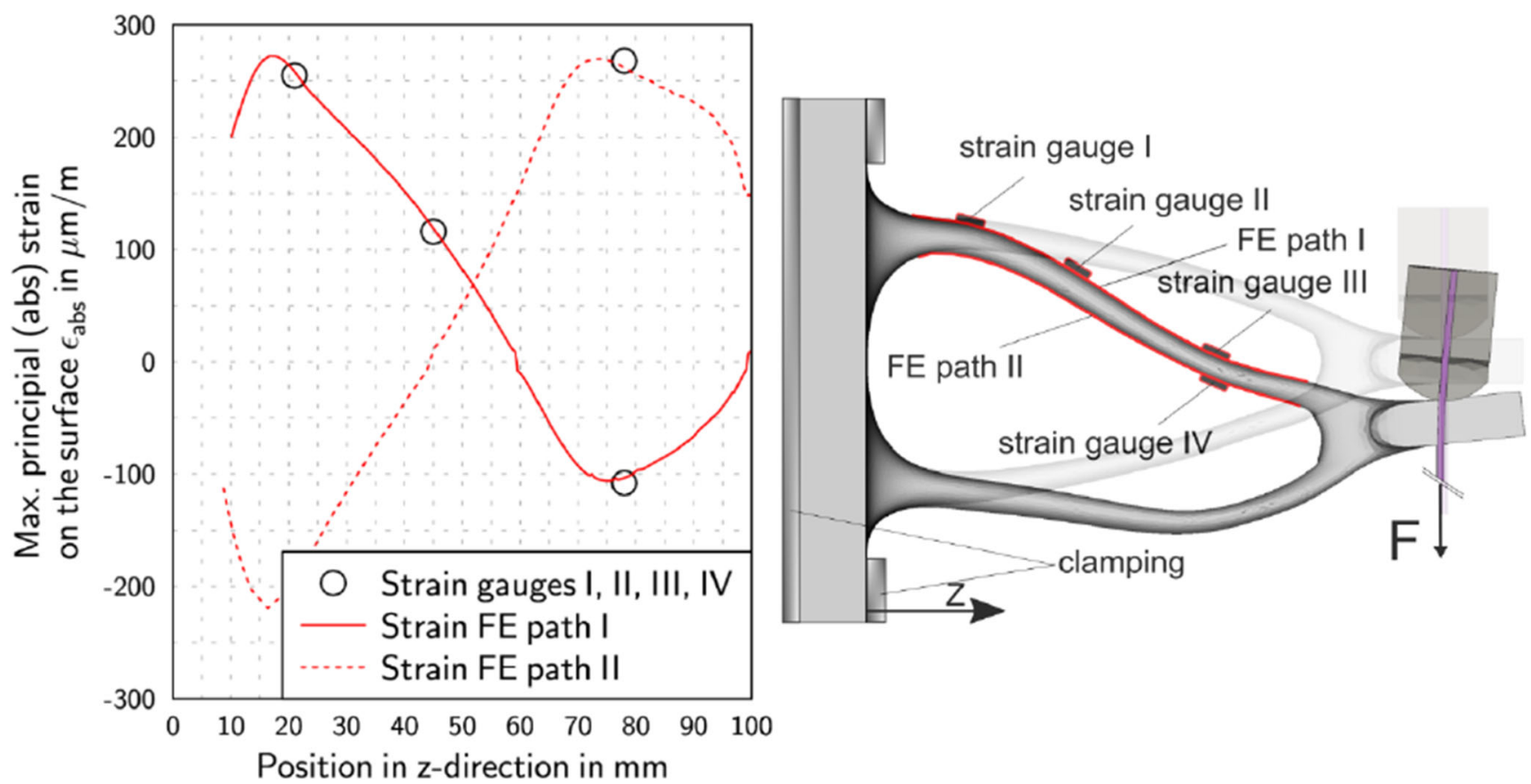

Fig. 16 Comparison of measured and calculated strains from the submodel for a load of $F=300 \mathrm{~N}$ and deformation appearance of the global model (deformation shown superimposed). 


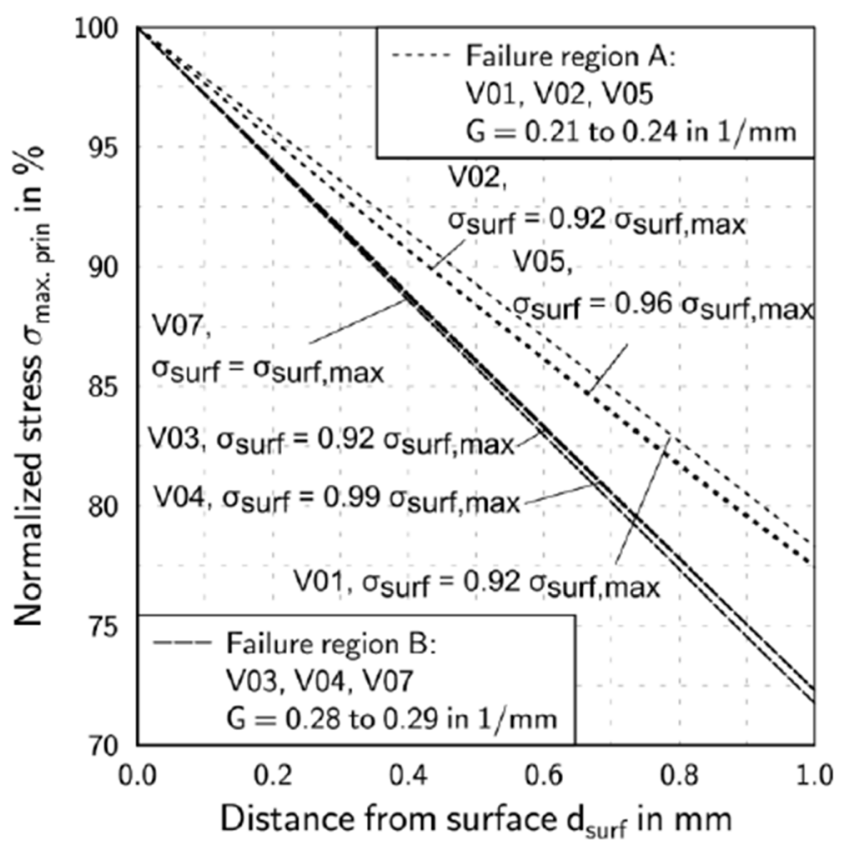

Fig. 17 Normalized stress gradients from the failure spots

levels are multiplied with the calculated normalized stress gradients $\eta$ in depth of the critical distance, which is found to be $a=0.2 \mathrm{~mm}$ for batch ALPHA as well as for batch BRAVO, by optimizing the scattering of test results. The optimization was performed by varying $a$ with a step size of $\Delta a=0.1$ between 0 and $1 \mathrm{~mm}$ depth. For this S-N curve, the knee point and the slopes of the unified values from the evaluation of the experimental results are used. This includes different values for normalized stress gradients $\eta$ for different notches. In the case of batch BRAVO, the experimental data have shown that the results for $K_{t}=1.0$ and $K_{t}=1.7$ lie on top of each other. As a pragmatic approach, the calculated normalized stress gradient for $K_{t}=1.7$ is also used for $K_{t}=1.0$. The resulting S-N curves are calculated using the maximum likelihood estimation, Fig. 18.

Based on the evaluated stress gradients of component-like structures, the stresses in a critical distance of $a=0.2 \mathrm{~mm}$ are calculated for the different load-amplitudes and compared with the effective stress S-N curves from batches ALPHA and BRAVO, Fig. 18.

With the calculated fatigue strength from batch ALPHA, the assessment of component-like structures leads to a nonconservative estimation. Using the calculated fatigue strength of batch BRAVO, the estimation of the component-like structures is conservative. In both cases, the experimentally identified cycles to fracture cannot be calculated satisfactorily.

Besides potentially different microstructures and slightly different pore distributions from the specimens to the component, this may be due to the fact that the applied concept mainly considers the geometric size effect based on the stress gradient. The gradients are rather flat $(0.21 \leq G \leq 0.29)$ in the component compared to the notched specimens $(G=1.32$ to $G=3.28$ ). The highly stressed material volume is thus more pronounced in the components and can influence more defects. Addressing the statistical size effect by using the highly stressed volume mentioned previously, the assessment quality could potentially be improved.
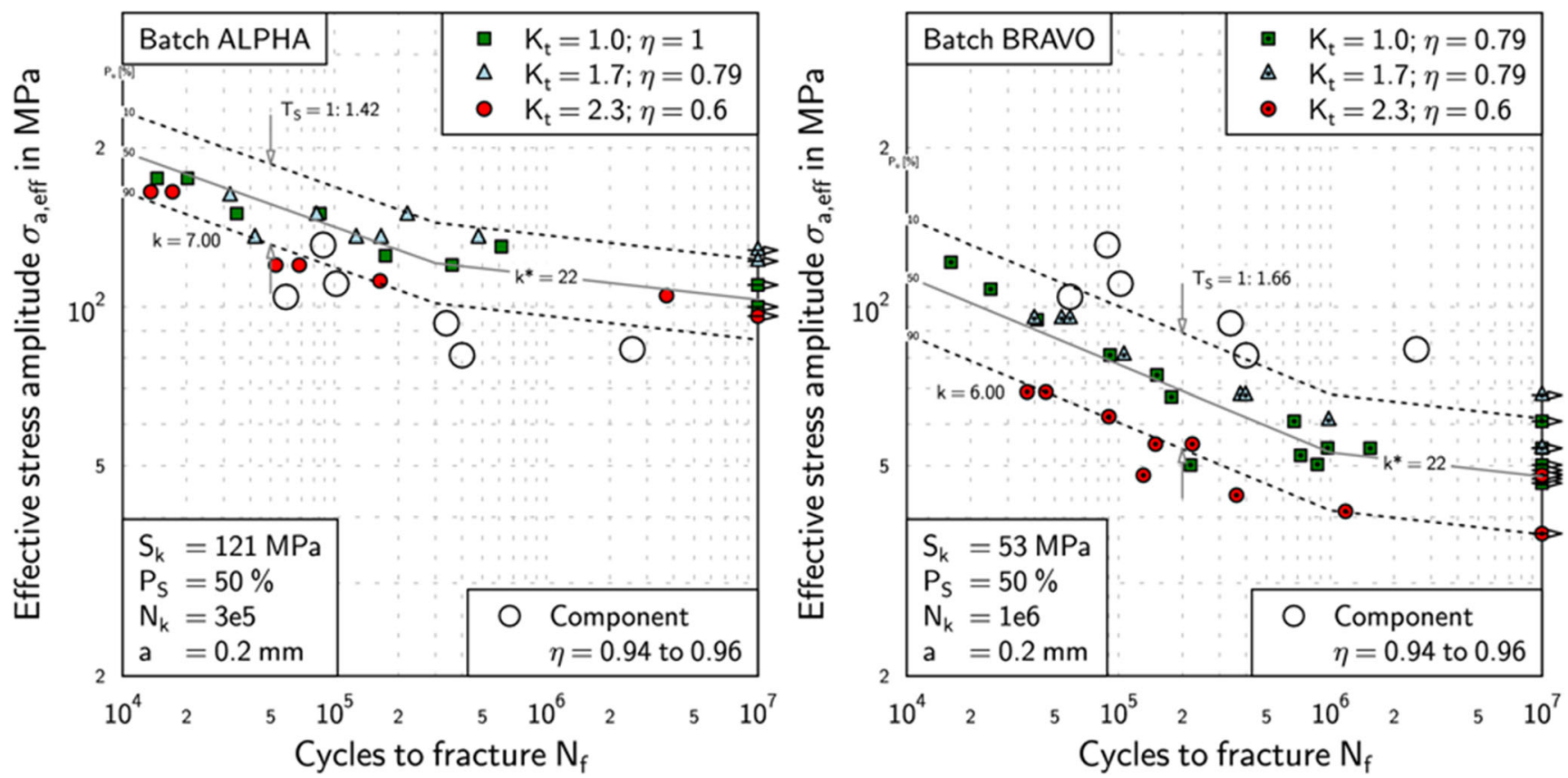

Fig. 18 Evaluated effective stress S-N curves of the un-notched and notched specimen of batch ALPHA (left) and batch BRAVO (right) with calculated effective stress results from the component-like structures 
Based on the results of the paper, possible reasons for the deviation between calculated and measured fatigue strengths of the components are:

- Different microstructures in the critical areas, mainly the contour area. This could be seen in the hardness measurements

- Scattering in the manufactured geometry and deviation from the nominal geometry in both batches ALPHA and BRAVO, which leads to different macro-geometrical notches

- Slightly different pore distribution and sizes in the specimen as well as in the component-like structures

- Unknown and possible deviating residual stress states between flat specimens and component-like specimens.

\section{Conclusion}

For safety-relevant components, a reliable fatigue assessment is indispensable. However, a reliable fatigue assessment of additively manufactured components is difficult to achieve due to a huge number of influencing factors on the microand macroscopic level of such components. Therefore, production quality and the effects of the individual quality influences on the final fatigue strength of the entire production chain are of decisive importance.

In general, a database of fatigue strength results and manufacturing conditions is necessary to build the basis for assessment concepts. In order to have comparable data available, this database requires all relevant information on the manufacturing process, e.g., scan strategy, the powder state. The correlations between the process and the resulting structure need to be examined more closely. Moreover, the process itself has to be evolved, taking into consideration the special requirements of fatigue strength. The verification of a building job in the accompanying specimen to be tested cyclically can therefore currently be recommended, if the components are cyclically loaded.

The experimental investigations have shown that despite the use of the same process parameters for additively manufactured AlSi10Mg, significant different results in the fatigue strength can be obtained. In retrospect, however, it is not possible to ensure that the gas flow was the same for both construction jobs used in the investigations presented. This shows how sensitive the manufacturing results are to parameter variations and how wide the influence on the fatigue strength can be. As an indication, differences in the measurement of the hardness of samples from the different building jobs were found in this investigation. The surface roughness showed slight differences, supporting the fatigue results, even though roughness indices should be considered with care for a fatigue assessment.
For the fatigue analysis using an effective stress concept with an assessment of stress in a critical distance of $a=$ $0.2 \mathrm{~mm}$ below the surface, the following differentiation from the assessment of the component-like structure based on two different databases from the batches ALPHA and BRAVO is achieved: using batch ALPHA as a basis a nonconservative assessment results, while batch BRAVO gives a conservative result. Even though both batches should be the same regarding their nominal process parameter sets, hardness measures indicate a slightly better agreement of batch BRAVO with the component-like structure of batch CHARLIE, providing possible explanations for the divergent results.

For the design of additively manufactured components, assessment concepts have to deal with the challenges of different defects in the structure and have still to be industrially applicable. It was shown that an effective stress concept could, in principle, be applicable, when the quality of the components to be assessed is the same quality of the used specimen-database. An improved assessment concept should also be able to take different defect distributions and microstructures into account, in order to deal with the different fatigue strengths from components built with nominally the same process parameters as well as locally differing material properties. Therefore the resulting defect distributions must be known a priori and depend on the process parameters. The approach of Representative Structural Elements could be a possibility to take different material properties, defect distributions and microstructures as a function of the process parameters and the local geometry into account for a numerical description and fatigue assessment of additively manufactured parts [35-37].

Acknowledgement The research and development project "VariKa", that forms the basis for this report, is funded within the scope of the "PAiCE Digitale Technologien für die Wirtschaft" technology program run by the Federal Ministry for Economic Affairs and Energy and is managed by the DLR project management agency „Gesellschaft, Innovation, Technologie-Informationstechnologien/Elektromobilität" at the German Aerospace Center in Cologne. The author is responsible for the content of this publication.

Funding Open Access funding enabled and organized by Projekt DEAL.

Open Access This article is licensed under a Creative Commons Attribution 4.0 International License, which permits use, sharing, adaptation, distribution and reproduction in any medium or format, as long as you give appropriate credit to the original author(s) and the source, provide a link to the Creative Commons licence, and indicate if changes were made. The images or other third party material in this article are included in the article's Creative Commons licence, unless indicated otherwise in a credit line to the material. If material is not included in the article's Creative Commons licence and your intended use is not permitted by statutory regulation or exceeds the permitted use, you will need to obtain permission directly from the copyright holder. To view a copy of this licence, visit http://creativecommons.org/licenses/by/4.0/. 


\section{References}

1. Scurria M, Möller B, Wagener R et al (2019) Effect of the surface finish on the cyclic behavior of additively manufactured AlSi10Mg. In: The minerals, Metals \& Materials Series: TMS 2019 148th annual meeting \& exhibition supplemental proceedings. Springer, Cham

2. Greitemeier D (2016) Untersuchung der Einflussparameter auf die mechanischen Eigenschaften von additiv gefertigtem TiAl6V4. Springer Fachmedien Wiesbaden

3. Beretta S, Romano S (2017) A comparison of fatigue strength sensitivity to defects for materials manufactured by AM or traditional processes. Int J Fatigue 94:178-191. https://doi.org/10.1016/j. ijfatigue.2016.06.020

4. Romano S, Beretta S, Brandão A et al (2017) HCF resistance of AlSi10Mg produced by SLM in relation to the presence of defects. Procedia Struct Integr 7:101-108. https://doi.org/10.1016/j.prostr. 2017.11.066

5. Persenot T, Burr A, Dendievel R et al (2020) Fatigue performances of chemically etched thin struts built by selective electron beam melting: experiments and predictions. Materialia 9:100589. https://doi.org/10.1016/j.mtla.2020.100589

6. Schnabel K, Baumgartner J, Wagener R (2019) Strukturelemente zur Berücksichtigung von Anisotropie und Inhomogenitäten in der rechnerischen Lebensdauerabschätzung von additiv gefertigten Bauteilen. In: Deutscher Verband für Materialforschung und prüfung e.V. (ed) Additiv gefertigte Bauteile und Strukturen: 4. Tagung des Arbeitskreises Additiv gefertigte Bauteile und Strukturen, Bericht 404, Berlin

7. O'Regan P, Prickett P, Setchi R et al (2016) Metal based additive layer manufacturing: variations, correlations and process control. Procedia Comput Sci 96:216-224. https://doi.org/10.1016/j.procs. 2016.08.134

8. Spears TG, Gold SA (2016) In-process sensing in selective laser melting (SLM) additive manufacturing. Integr Mater Manuf Innov 5:16-40. https://doi.org/10.1186/s40192-016-0045-4

9. Cordova L, Campos M, Tinga T (2019) Revealing the effects of powder reuse for selective laser melting by powder characterization. JOM 71:1062-1072. https://doi.org/10.1007/s11837-0183305-2

10. Wycisk E, Emmelmann C, Siddique S et al (2013) High cycle fatigue $(\mathrm{HCF})$ performance of Ti-6Al-4V alloy processed by selective laser melting. Adv Mater Res 816-817:134-139. https://doi. org/10.4028/www.scientific.net/amr.816-817.134

11. Bagehorn S, Wehr J, Maier HJ (2017) Application of mechanical surface finishing processes for roughness reduction and fatigue improvement of additively manufactured Ti-6Al-4V parts. Int $\mathbf{J}$ Fatigue 102:135-142. https://doi.org/10.1016/j.ijfatigue.2017.05. 008

12. Stoffregen H, Butterweck K, Abele E (2014) Fatigue analysis in selective laser melting: review and investigation of thin-walled actuator housings. In: Solid freeform fabrication proceedings: 25 th solid freeform fabrication symposium 2014. University of Texas, Austin, pp 635-650

13. Chan KS, Koike M, Mason RL et al (2012) Fatigue life of titanium alloys fabricated by additive layer manufacturing techniques for dental implants. Metall Mater Trans A 44:1010-1022. https://doi. org/10.1007/s11661-012-1470-4

14. Brandão AD, Gumpinger J, Gschweitl M et al (2017) Fatigue properties of additively manufactured AlSil0Mg surface treatment effect. Procedia Struct Integr 7:58-66. https://doi.org/10.1016/j. prostr.2017.11.061

15. Konečná R, Nicoletto G, Fintová S et al (2017) As-built surface layer characterization and fatigue behavior of DMLS Ti6Al4V. Procedia Struct Integr 7:92-100. https://doi.org/10.1016/j.prostr. 2017.11.065

16. Siddique S, Imran M, Wycisk E et al (2015) Influence of processinduced microstructure and imperfections on mechanical properties of AlSi12 processed by selective laser melting. J Mater Process Technol 221:205-213. https://doi.org/10.1016/j.jmatprotec.2015. 02.023

17. Benedetti M, Fontanari V, Bandini M et al (2018) Low- and highcycle fatigue resistance of Ti-6Al-4V ELI additively manufactured via selective laser melting: mean stress and defect sensitivity. Int J Fatigue 107:96-109. https://doi.org/10.1016/j.ijfatigue.2017.10. 021

18. Christ H-J (2009) Ermüdungsverhalten metallischer Werkstoffe, 2nd edn. Weinheim, WILEY-VCH

19. Wagener R (2007) Zyklisches Werkstoffverhalten bei konstanter und variabler Beanspruchungsamplitude. Dissertation, TU Clausthal

20. Salmi A, Atzeni E, Iuliano L et al (2017) Experimental analysis of residual stresses on AlSi10Mg parts produced by means of selective laser melting (SLM). Procedia CIRP 62:458-463. https://doi.org/ 10.1016/j.procir.2016.06.030

21. Sonsino CM (2009) Effect of residual stresses on the fatigue behaviour of welded joints depending on loading conditions and weld geometry. Int J Fatigue 31:88-101. https://doi.org/10.1016/j. ijfatigue.2008.02.015

22. Wagener R, Scurria M, Möller B (2018) Einflüsse auf das zyklische Spannungs-Dehnungsverhalten von additiv gefertigten Strukturen aus AlSi10Mg. In: Deutscher Verband für Materialforschung und prüfung e.V. (ed) Additiv gefertigte Bauteile und Strukturen: 3. Tagung des Arbeitskreises Additiv gefertigter Bauteile und Strukturen, Berlin

23. Scurria M, Möller B, Wagener R et al (2019) Characterization of the cyclic material behavior of AlSi10Mg and Inconel 718 produced by SLM. In: Mechanical fatigue of metals: structural integrity, vol 7. Springer, Cham

24. Scurria M, Möller B, Wagener R et al (2018) Einfluss der Oberflächenbehandlung und Aufbaurichtung auf das zyklische Spannungs-Dehnungs-Verhalten von additiv gefertigten Strukturen aus Inconel 718. In: Deutscher Verband für Materialforschung und -prüfung e.V. (ed) Additiv gefertigte Bauteile und Strukturen: 3. Tagung des Arbeitskreises Additiv gefertigter Bauteile und Strukturen, Berlin

25. Sola A, Nouri A (2019) Microstructural porosity in additive manufacturing: the formation and detection of pores in metal parts fabricated by powder bed fusion. J Adv Manuf Process:1. https:// doi.org/10.1002/amp2.10021

26. Schnabel K, Baumgartner J, Wagener R (2019) Fatigue assessment of additively manufactured metallic structures using local approaches based on finite-element simulations. Procedia Struct Integr 19:442-451. https://doi.org/10.1016/j.prostr.2019.12.048

27. Aboulkhair NT (2015) Additive manufacture of an aluminium alloy: processing, microstructure, and mechanical propertie. University of Nottingham, Dissertation

28. Prashanth KG, Eckert J (2017) Formation of metastable cellular microstructures in selective laser melted alloys. J Alloys Compd 707:27-34. https://doi.org/10.1016/j.jallcom.2016.12.209 
29. Spindel JE, Haibach E (1979) The method of maximum likelihood applied to the statistical analysis of fatigue data. Int J Fatigue 1:8188. https://doi.org/10.1016/0142-1123(79)90012-4

30. Sonsino CM (2007) Course of SN-curves especially in the highcycle fatigue regime with regard to component design and safety. Int J Fatigue 29:2246-2258. https://doi.org/10.1016/j.ijfatigue. 2006.11.015

31. Rennert R, Kullig E, Vormwald M et al. (2013) FKM guideline analytical strength assessment of components(6)

32. Kuguel R (1961) A relation between theoretical stress concentration factor and fatigue notch factor deduced from the concept of highly stressed volume. In: Sixty-fourth Annual Meeting of the Society (ASTM), pp 732-744

33. Baumgartner J, Lipp K, Bruder T et al (2011) Design methods for reliable fatigue assessment of PM components. Mater Werkst 42: 894-903. https://doi.org/10.1002/mawe.201100869

34. Taylor D (1999) Geometrical effects in fatigue: a unifying theoretical model. Int J Fatigue 21:413-420. https://doi.org/10.1016/ S0142-1123(99)00007-9
35. Wagener R, Hell M, Scurria M et al (2020) Deriving the structural fatigue behavior of additively manufactured components. In: The Minerals, Metals \& Materials Society (ed) TMS 2020 149th annual meeting \& exhibition supplemental proceedings. Springer, Cham

36. Wagener R, Möller B, Scurria M et al (2020) A fatigue life approach for additively manufactured structures. In: The Minerals, Metals \& Materials Society (ed) TMS 2020 149th annual meeting $\&$ exhibition supplemental proceedings. Springer, Cham

37. Melz T (2021) FB-263: Guideline: Fertigung betriebsfester Bauteile mittels PBF-LB/M Verfahren - Vom Pulver bis zum Bauteilversagen. Schriftenreihe LBF-Berichte. Fraunhofer LBF, Darmstadt (in press)

Publisher's note Springer Nature remains neutral with regard to jurisdictional claims in published maps and institutional affiliations. 